\title{
Achieving Sustainability*
}

\section{Michael James Platts}

Institute for Manufacturing, University of Cambridge, Cambridge, UK

Correspondence to: Michael James Platts, mjp@eng.cam.ac.uk

Keywords: Sustainability, Flow of Qi, Tree of Life, Mindset, Conceptual Shift, Achievement Motivation, Reflective Wisdom, Symbiotic Relationships

Received: May 12, $2021 \quad$ Accepted: July 25, $2021 \quad$ Published: July 28, 2021

Copyright $\odot 2021$ by author(s) and Scientific Research Publishing Inc.

This work is licensed under the Creative Commons Attribution International License (CC BY 4.0).

http://creativecommons.org/licenses/by/4.0/

\section{(c) (i) Open Access}

\section{ABSTRACT}

Although all the symptoms of lack-of-sustainability are physical, the cause is a mindset that needs to be changed. The mindset includes an addictive lock on wanting materialistic solutions to all problems, most of which are not materialistic, but are existential problems about meaningfulness in life. Meaningfulness is an inner understanding about life that is only achieved by insightful reflective thought. This kind of growth is enabled by the right kind of caring leadership that enables people to realise and properly establish their existential relationship with Nature.

\section{ROOT CAUSE ANALYSIS}

Western doctors always maintain that seeing patients face-to-face is important. The patient will come in to the room, sit down and discuss the physical illness and the doctor will prescribe appropriate treatment, but very often, as the patient is getting up to leave, they will make an offhand remark, and following up that offhand remark leads the doctor to a far deeper insight as to the root cause of the illness. What is well known is that a very high proportion of physical illness is actually psychosomatic in origin and the physical illness is merely a surfacing of this deeper disease. Treating the physical illness is of course necessary, but it does not address the root cause and the disease will continue to manifest in different ways until it itself is treated.

In problem solving in manufacturing industry, this same understanding is well established in the root *This paper is not a conventional academic paper, it is written from within the wisdom tradition, which assumes that the reader has a deeply meditative way of thinking. But in the modern world this is largely an undeveloped skill. If you try and read the 81 passages of Lao Tzu's Tao Te Ching as a book, for instance, you will gain nothing. In his translation of the Tao Te Ching into English, Wing gives 15 pages of very clear instructions at the beginning of the book, explaining not only how to "read" it but how to think about it, so that you will develop the deeper and more useful way of thinking that the Tao Te Ching represents (Wing, R.L, The Tao of Power, Aquarian Press, London 1986). This paper, similarly, is actually about a way of thinking and is written to be "read" in this meditative, reflective way. 
cause analysis process known as "the five why's". You need to pay sensitive attention to seemingly small and irrelevant details and reflectively ask yourself the question "Why did that happen?", and then openly ask the same question, sequentially five times. (Asking the question openly brings it into consciousness, whereas a small, reflective personal thought will fade from consciousness.) What this process reveals is a root cause far removed from the actual manifestation of the problem and not "obvious" at all, but of great significance. Resolving this root problem removes the "fault" which surfaces in the manufacturing process and becomes embedded in the product. This process of pursuing seemingly small details through root cause analysis is key to achieving quality assurance in manufacturing processes. The same is true of the process needed to achieve sustainability in human life.

\section{SEEMINGLY SMALL REMARKS}

The paper Soil Fertility is a Productive Capital Asset [1] was looking at a blind spot in human behaviour. But it only tells half the story. It is now appropriate to tell the deeper half of the story. Within that paper there is one example of the process illustrated by the doctors, of following up a seemingly aside remark. In the final editing process, whilst checking that the practitioner observations were being well represented, Khirel Anuar Ismail commented that he still wasn't happy. Sensitively asking why drew out the comments about why government officials rarely follow up initiatives such as the development and application of OrganiGro. But there is a deeper and far more important example.

Years before seeking their assistance in developing the paper, in a conversation discussing the whole process of developing and exploring the value of OrganiGro, YAM Dato' Seri Syed Razlan Syed Putra Jamalullail made two offhand remarks that are in fact leading remarks. At one point in the conversation he simply said-but said with considerable energy and with joy shining in his face-"You can see the vibrancy in the plants!" It is important to note at this point that vibrancy never occurs in only one part of an ecosystem. Either the whole ecosystem is vibrant or vibrancy is not there. "Vibrancy"-is the flow of life... what the Chinese would call "qi". What he was saying in this comment was that he could "see" it (i.e. sense it), in the treated plantations he was looking at. But, further than that, at a later point in the conversation, he commented that, when OrganiGro was shown to be successful, he was asked why he didn't start a company to pursue the development further. But he simply said that he wasn't interested in doing that. This is not a small remark. What he was saying was that, for him, "seeing" the vibrancy was reward enough and he did not want more. It is this point that will be followed up here. What he was actually saying was that he was not merely "seeing" the vibrancy, he was sharing in it. It was giving him vibrancy too. This is a key observation.

\section{HEALING DISEASE}

Noting that much disease is psychosomatic in origin is an important starting point, but needs clarification. What is usually called the health profession actually focuses on understanding and treating illness, and in a similar way, most psychological work focuses on understanding and treating psychological illness. Studying what is pathological is of course necessary but it is not sufficient to create health. It needs to be balanced by what is called developmental psychology, which has two zones within it. One is child development psychology, which some people understand. The deeper levels of human development are less well studied, but are in fact well understood, if only by a few people, in the different wisdom traditions that underlie the different civilisations across the planet. It is to this teaching that this analysis now turns, as what is in hand when we confront the global issue of human sustainability is in fact an existential question and can only be understood and dealt with at this deep level.

Universities are incredibly good at teaching you to be clever. But how do you become wise? There are extant lines of wisdom teaching in all civilisations, that are far older than the world's universities but only ever pass understanding person to person, essentially invisibly, only involving those who are deeply reflective enough to have found their way to the door and have dedicated themselves to the quiet inward listening required. They seek to understand how Creation actually works, which is, here, what we need to know. 
So, it is to this teaching that we now turn for guidance.

\section{THE TREE OF LIFE}

Concerning how Creation works, the descriptive model used by all the wisdom traditions is called The Tree of Life [2], which is essentially always expressing the same truths but using different imagery to fit the "languages" of different civilisations. Diagrammatically, it always involves two sides covering structure-giving elements on one side and energising elements on the other (yin and yang), either side of a central balancing column (Tao-“The Way") diagrammatically illustrating growth in depth upwards and the flow of Life (the flow of qi) downwards (Figure 1). The layout of the Forbidden City in Beijing is the Tree of Life "map" embodied in stone [3] (Figure 2). The western variant of this teaching is the foundational model of western psychology [4] (Figure 3) and Abraham Maslow's work on the seven hierarchical levels of human developmental needs [5] maps directly on to it (Figure 4), given sharper focus for our present purposes here by David McClelland's associated work on achievement motivation [6]. Maslow's work enables us to see both where (at what level) and how human psychological development gets stuck, and that is what we need to know.

In developing descriptive terms for Maslow's seven levels, so that they are easily recognisable by the layman, Kirk MacNulty provides a good starting point [7], enabling the seven levels to be grouped into three recognisable steps of growth towards real maturity. They are as follows.

The first two developmental stages, "aimless" and "survivor", describe in the first case the physically needy infant that can do nothing for itself, contrasting with the second stage, where the ability to sustain yourself physically is established. The second pair concerns the development of social identity. In the first of these, a "belonger" derives their identity from outside (e.g. they will describe themselves by naming their job), whereas in the next stage "conspicuous consumers" create their own identity via their possessions. In both these stages the source of their "sense of self" is entirely external to themselves and it is

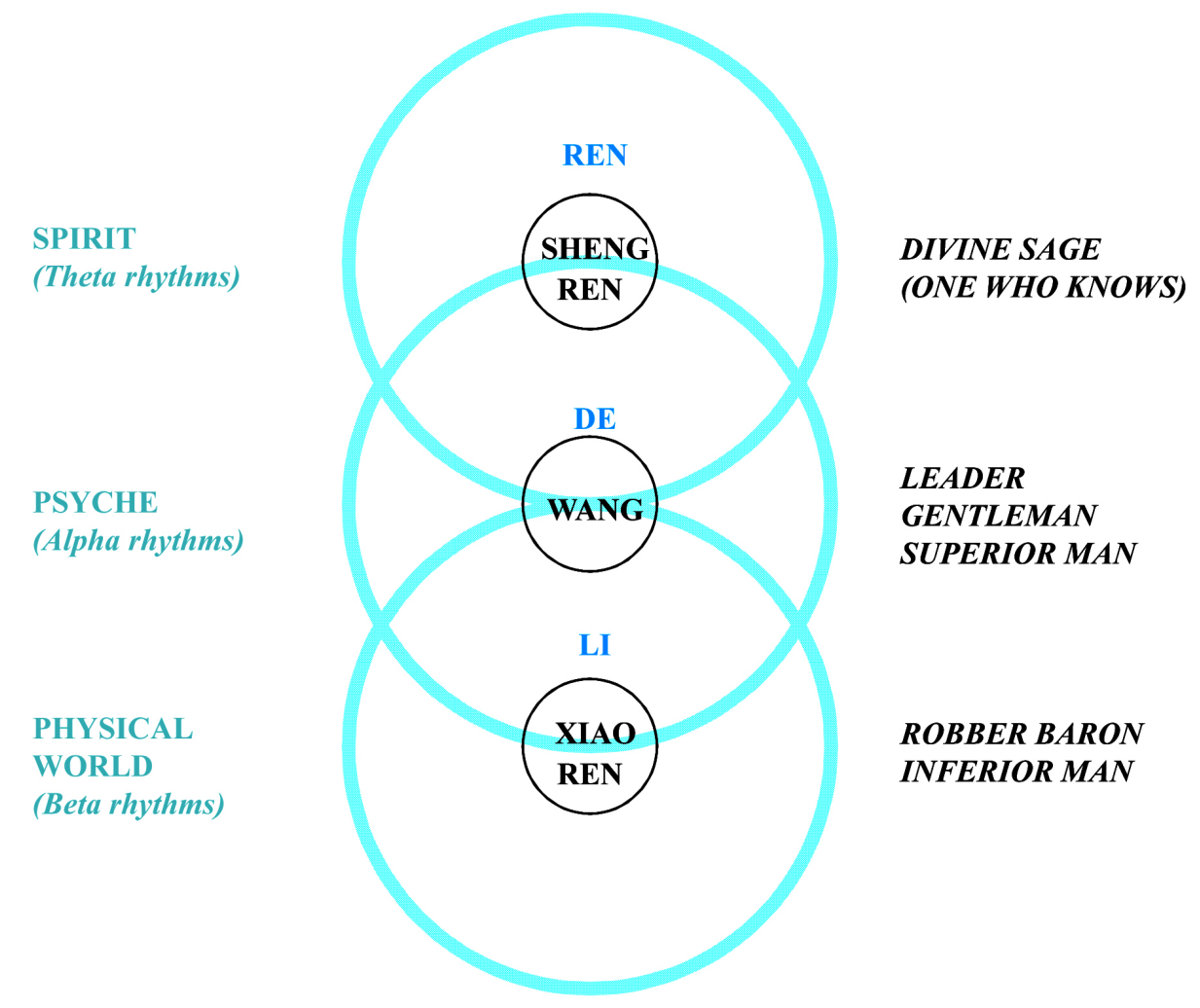

Figure 1. Levels of Chinese wisdom. 


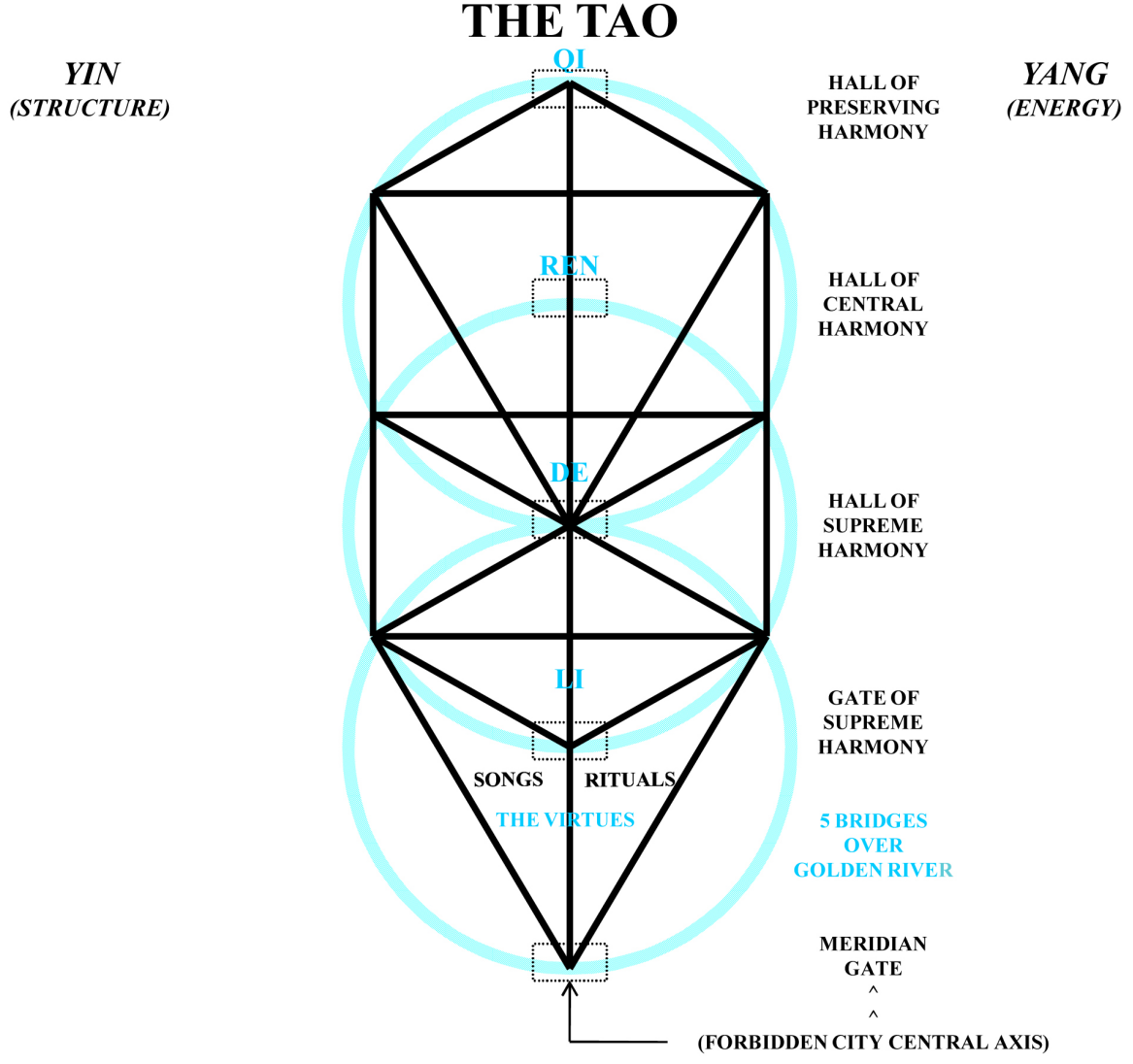

Figure 2. The Tao mapped on to the forbidden city.

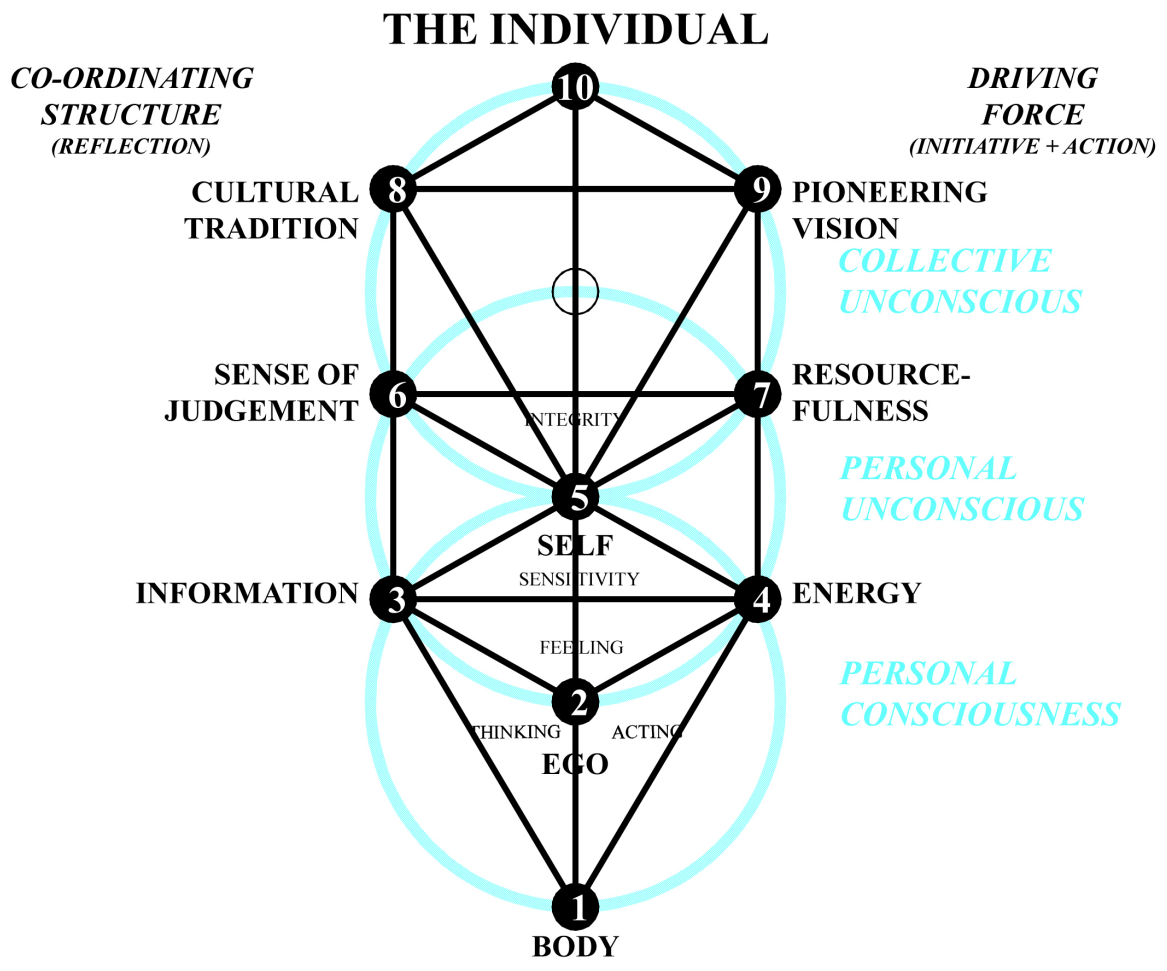

Figure 3. Western psychology mapped on to the tree of life. 


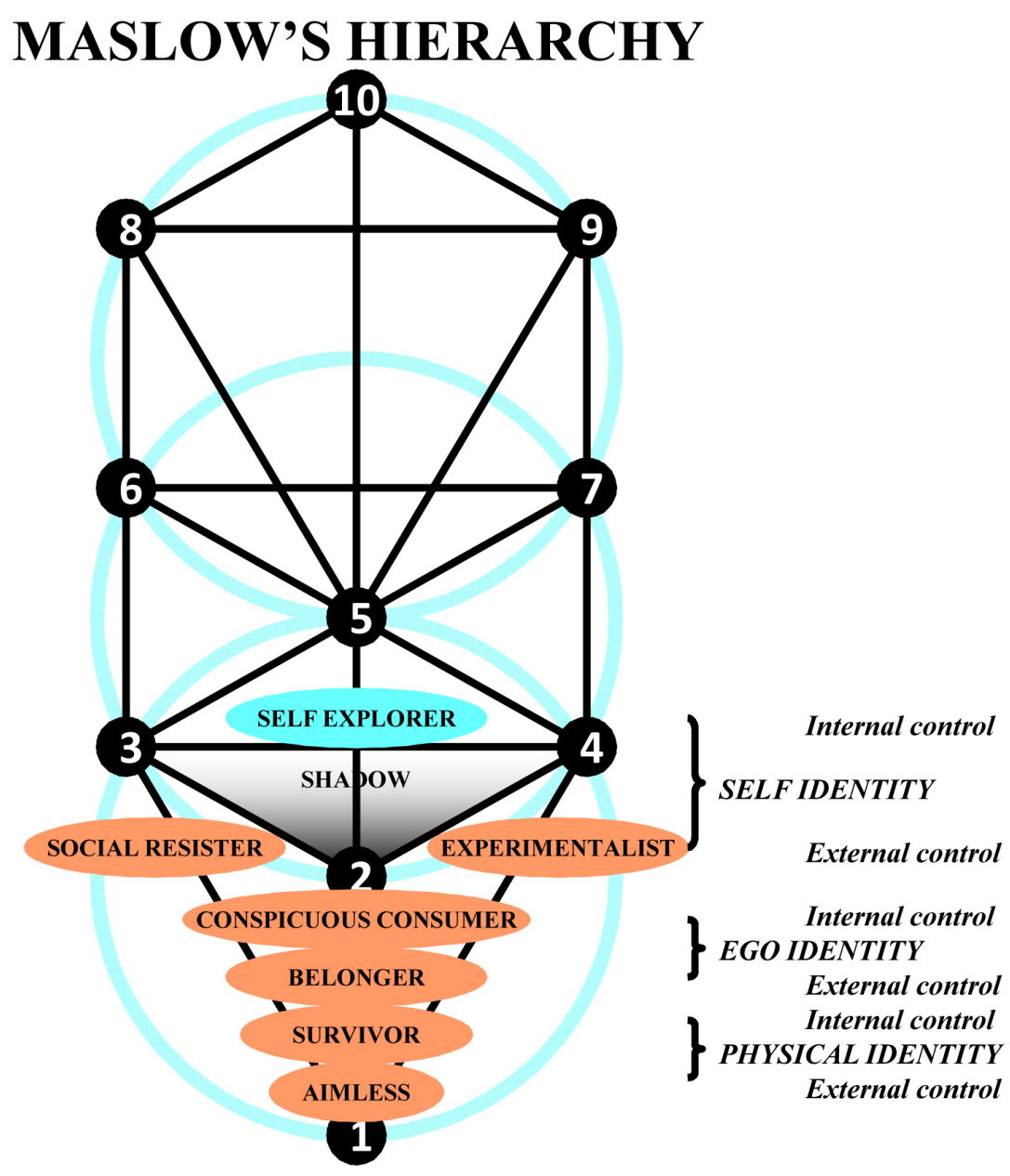

Figure 4. Maslow's hierarchy of human psychological needs mapped on to the tree of life.

established wilfully, by "wants" that are "asserted", i.e. it is constructed by assembling outer choices, not by inner growth.

In psychological terms this is the creation of an external "persona" (a mask) which is presented to the outer world, but it is not actually "real" in that it has no actual foundation in the inner self of the person. That is not yet developed. This is where the difficulty begins, and is well described in McClelland's discussion of "achievement motivation", in which he carefully distinguishes between outward "success", which involves no internal growth, and "achievement", which is entirely about internal growth of the self towards wholeness.

Maslow's next two stages form a pair and contrast strongly with what he identifies not only as the final stage but as the target of the whole psychological developmental process. These two stages, of being a "social resister" or being an "experimentalist", both seek an internal result (the first seeks a structuring result that keeps something in control and the second seeks an energising result that is exciting) but they still seek it from outside and try to demand the result by wilful assertion. This contrasts with the final stage, the "self-explorer", who (finally) takes inward responsibility for achieving the growth that will make them psychologically whole and content.

\section{5. “WANTING” IS AN EMOTION. IT IS NOT A THINKING PROCESS}

The danger of both the "conspicuous consumer" stage and the "social resister" and "experimentalist" 
stages is that they are driven by the will, and the problem of the will is that wilfulness prevents the development of the insights necessary for psychological growth and the development of psychological wholeness. All three stages tantalise, in that they seem to offer "the answer", but they do not in fact satisfy, i.e. no growth is achieved. But wilfulness assumes that the need is to push harder, and that "more" will satisfy and this has the effect of creating an addiction. The psychological problem, then, is how to break the addiction, because the one thing an addict cannot talk about is the addiction itself. In our context here, humanity has spent the last three centuries developing a strong addiction to material wealth, the extensive use of energy and endless travel. It does not bring psychological wholeness. But it is now crippling the planet and is clearly not sustainable.

To be precise, and to return to the notion of a root cause, the problem is that wilfulness is not a thinking process at all. There is no reflection. It is in fact only a choosing process, followed by an insistence that the chosen answer is the answer. It is thus an action process rather than a reflection process and it absolutely destroys the possibility of any kind of insight, because its own opinion is absolute and final. However, wants are not needs. They tantalise, but pursuing them does not feed inner growth. "More" is not "better", but it becomes addictive. To get beyond this mindset "trap" requires inspirational leadership.

\section{WISDOM IS NEEDED}

Again and again, throughout the millennia of recorded guidance from within the wisdom tradition, the nature and the result of this addiction is pointed out and warned against ("Power tends to corrupt, and absolute power corrupts absolutely...", to quote Lord Acton), and all images of wise old men and wise old women are of people owning hardly anything, living very simply and able to be found easily because they do not move from where they are. All their journeying has been inwards (which involves a different kind of effort), and they really do understand how Creation works, and their place in it, and they are content. We cannot achieve a shift to sustainability by keeping the desires we have and wanting a technical fix to allow us to keep them. That is what the addict will of course want. But living sustainably is not about power, it is about insight, and it is this shift in mindset that we need. So, it is to this guidance that we now turn.

\section{THE CARE AND GROWTH MODEL OF LEADERSHIP}

A good leader doesn't "teach" you. They inspire you. What generates their authority is their authenticity. The person is clear-sighted in what they set out to do. They do not take. They have the ability to give and they visibly do so, open-handedly. Power generates fear. Open-handed authenticity encourages. Four axioms are involved.

- What is at issue between a leader and a follower is not the value of a commodity called labour but the validity of authority.

- Authority is validated if the result of the interaction is the authorisation of the subordinate.

- Authorisation implies the transmission of understanding and an incremental suspension of control in order to enable the subordinate to become capable and responsible.

- Maturity is being here to serve, and acting with magnanimity and courage.

What came to be called the "Care and Growth" model of leadership emerged from work in post-Apartheid South Africa, by Etsko Schuitema, wanting to heal the broken relationships in that country [8]. He interviewed thousands of people, asking them what they thought the characteristics of a good leader were, and gave them plenty of time to develop their responses. What amazed him was that not only did the same ten items emerge over and over again, they emerged in the same order. And he came to realise that they concerned either care, or growth, hence the name of the leadership model. Those ten characteristics are as follows.

The leader listens Care

The leader is sympathetic Care

The leader is sincere Care 
The leader has a sense of humour

Care

The leader is honest

Growth

The leader gives me consistent feedback

Growth

The leader is fair

Growth

The leader rewards me fairly

Growth

The leader recognises my contribution

Growth

The leader gives me freedom to do my own thing Growth

The leader is concerned about me as a whole person Care

The Care and Growth model of Leadership became the core of the teaching within the Cambridge Manufacturing Leaders' Programme, and absorbing those insights into their behaviour was recognised as the most valuable part of their personal growth by almost all of the participants in that programme. It is these characteristics that can be seen in YAM Dato' Seri Syed Razlan Syed Putra Jamalullail's remarks. There is no "wanting" and there is a clear sense of achievement, not only in having recognised the presence of vibrancy in the whole ecosystem, but in having been able to assist in its development, i.e. in having been participatory in its flow-a recipient as well as a collaborator in and with Creation. This is a relationship both of insight and of respect, not in any way a relationship of dominance, and it brings a sense of awe at the greatness of it all.

But there is a deeper "rightness". One of the things deeply understood in the wisdom tradition is, wisdom - real wisdom - cannot be bought or sold. It can only ever be given... because the one thing you do know is that you don't own it. When an insight dawns on you, you realise that something is true (blindingly obviously true), but more than that, you realise that it is true in and of itself, it is not "true" because an important person says it is, i.e. you have learnt something about truth itself, and that truth doesn't leave you. You can't own it. It "owns" itself. So, you learn something about humility, too. This quiet, insightful gentleness is apparent in other initiatives in South East Asia, for instance in the work of the Enchanted Farm in the Philippines and in the work of IBEKA in Indonesia [9]. They show that caring enables growth... and that is all we need to know. IBEKA's guidelines for community empowerment are shown in Figure 5.

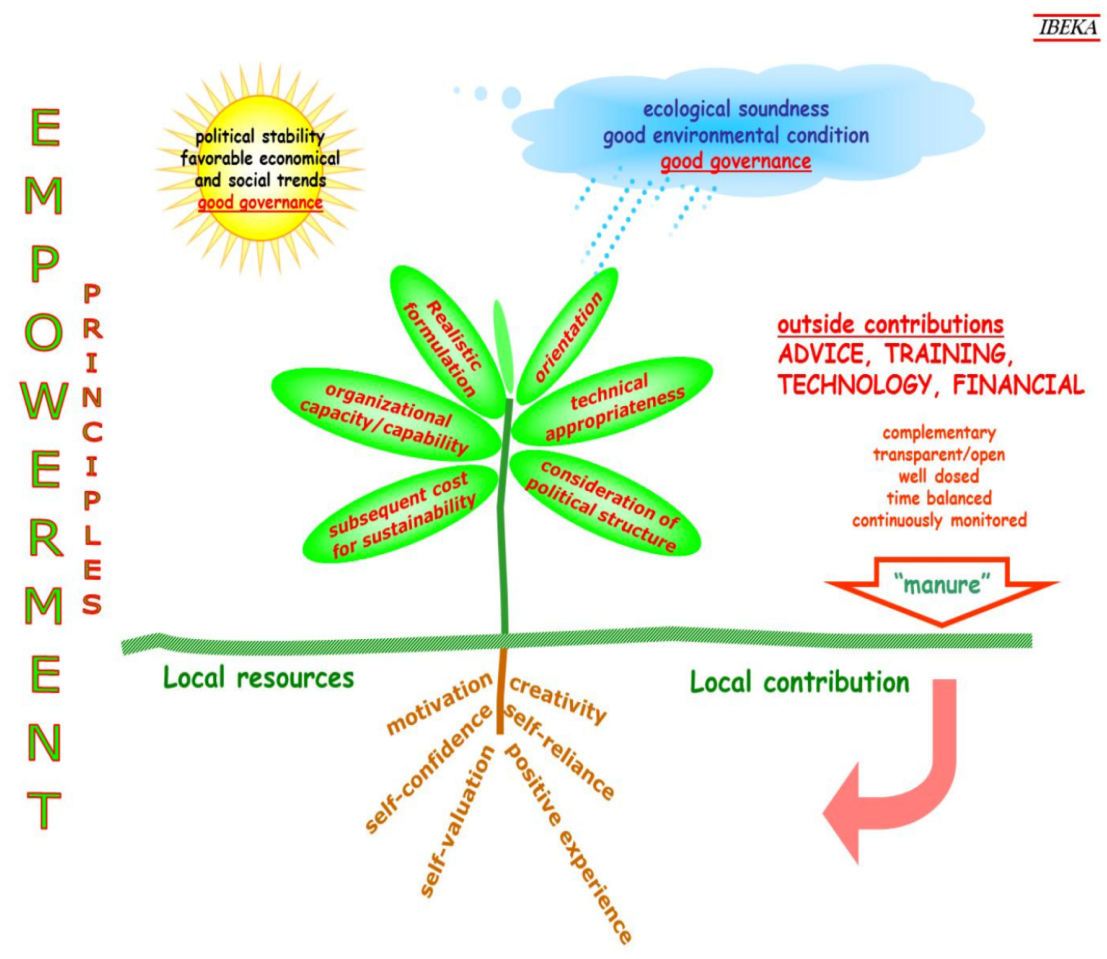

Figure 5. IBEKA's guidelines for community empowerment. 
The key leadership insight is.

\section{FOLLOW NATURE'S LEAD}

And the key technical insight is.

\section{CHEMISTRY IS OUTCLASSED BY NATURE'S ATTENTION TO DETAIL}

Both are about collaboration.

Life is primarily built of hydrogen, carbon and oxygen, progressing from small to large, micro-step by micro-step. It pays to understand the detail of how this is done. Each micro-step is reliably and resiliently effective, very precise and incredibly efficient, and so creates a reliable building block for higher level creation. Nothing is left to chance.

Whereas mankind produces materials at large scale using chemical processes that involve high temperatures, significant inefficiency and the production of considerable quantities of waste, Nature builds in a very focused way, atom by atom, molecule by molecule, locally, where and when it is needed, at ambient temperature, with no inefficiency and no waste. Each molecular manipulation is done for a particular purpose in a particular context, done by a particular micro-organism created and supported by the surrounding organisms within the collective ecosystem to do precisely that, and capable of being replicated elsewhere, wherever that creative function is needed.

Each particular micro-organism is very precisely focused. It knows what to do and it knows how to do it so that the process consistently and without any struggle gives correct embodiment to the intent, wherever and whenever it is required, creating it locally within the context in which it is required. And the context it is in is a network of supportive symbiotic relationships with other micro-organisms which together form a complete ecosystem in which they all thrive continuously, collectively forming a higher-level organism able to fulfil a higher-level function.

It is informative to examine in detail how hydrogen, carbon and oxygen are manipulated to both create and sustain Life. How do you create the hydrocarbons from which you yourself are created? It is all about molecular and atomic manipulation and it is a team effort, with one crucial input-radiant energy-from an external, non-hydrocarbon source.

But that is a story for a different day, summarised in the Tree of Life diagram below (Figure 6). For now, what we need to understand is, collaboration is what matters.

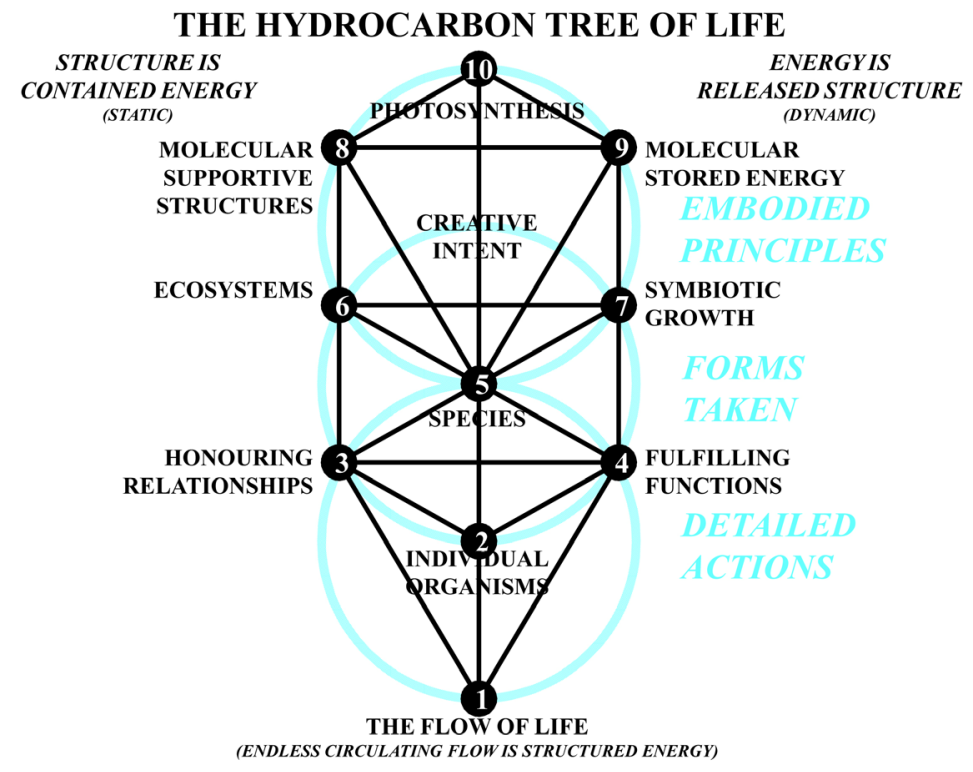

Figure 6. The hydrocarbon tree of life. 


\section{CONFLICTS OF INTEREST}

The author declares no conflicts of interest regarding the publication of this paper.

\section{REFERENCES}

1. Platts, M.J. and Leong, Y.Y. (2020) Soil Fertility Is a Productive Capital Asset. Agricultural Sciences, 11, 744-776. https://doi.org/10.4236/as.2020.118049

2. Halevi, Z.S. (1979) Kabbalah Tradition of Hidden Knowledge. Thames \& Hudson, London.

3. Platts, J. (2013) The Fault Line in Chinese Reflective Thinking. Philosophy Study, 3, 945-957.

4. Halevi, Z.S. (1986) Kabbalah and Psychology. Gateway Books, London.

5. Maslow, A.H. (1970) Motivation and Personality. Harper \& Row, New York.

6. McClelland, D.C. (1961) The Achieving Society. Van Nostrand, Princeton. https://doi.org/10.1037/14359-000

7. MacNulty, W.K. (1985) UK Social Change through a Wide-Angle Lens. Futures, 17, 331-347. https://doi.org/10.1016/0016-3287(85)90077-1

8. Schuitema, E. (1998) Leadership. Ampersand, Cape Town.

9. Hardjosoekatmo, J. (2012) Rural Electrification in Indonesia: Exploring the Cooperative Model for Increasing Energy Access. M.Phil. Thesis, University of Cambridge, Cambridge. 